\title{
International conference on novel methods for subsurface characterization and monitoring: from theory to practice: NovCare 2017
}

\author{
Uta Koedel ${ }^{1}$
}

Received: 23 August 2018 / Accepted: 10 September 2018 / Published online: 18 September 2018

(c) Springer-Verlag GmbH Germany, part of Springer Nature 2018

\begin{abstract}
The NovCare 2017 International Conference (Novel Methods for Subsurface Characterization and Monitoring: From Theory to Practice) took place in June 2017 and was the fifth conference in a series that has proven to be an excellent forum for exchanging ideas and experiences related to the challenges of subsurface characterization and monitoring. Some of the presented work is included in this Thematic issue NovCare 2017.
\end{abstract}

Keywords Conference $\cdot$ NovCare $\cdot$ Subsurface monitoring

There is a pressing need to improve our understanding of the subsurface, and to better monitor and characterize systems affected by natural and anthropogenic influences by applying several direct and indirect tools. These tools have high accuracy and suitable resolution across a range of spatial and temporal scales. Subsurface monitoring should address these challenges through selecting and implementing a variety of monitoring tools that are both technically robust, minimal invasive, and cost-effective, and through providing an effective means of investigating near surface structures, identification, and parameterization relevant physical-chemical-biological processes, characterization interactions between different scales, and even to detect any unforeseen events such as gas leakages or sink holes. Some of these tools for subsurface characterization and monitoring have reached a highly sophisticated level as a result of decades of utilization in, e.g., the oil and gas exploration. Therefore, this tool box has been adapted to overcome the shortcomings and restrictions for monitoring and characterizing accurately and precisely aquifers, soils, and watersheds. Such a tool box of several techniques can also be used collaboratively with numerical models to help verify that subsurface processes

Uta Koedel

uta.sauer@ufz.de

1 Helmholtz Centre for Environmental Research-UFZ, Permoserstr. 15, 04318 Leipzig, Germany and interactions are taking place as predicted as well as to improve the predictive capabilities of numerical models.

Further development of monitoring technologies, of strategies for investigation, of sampling and interpretation as well as of novel approaches and models is essential to improve the effectiveness of such a tool box for subsurface monitoring. The purpose of the International Conference series NovCare (Novel Methods for Subsurface Characterization and Monitoring: From Theory to Practice) is showcasing such novel developments and highlighting the examples of field applications of relevant approaches such as geophysics, direct-push technology, hydrogeological and hydrogeochemical field methods, joint inversion of multi-method data, in-situ measurements, wireless sensor networks, and remote-sensing techniques. In addition, the NovCare conference provides a rare opportunity and an outstanding platform for researchers and practitioners from all over the world to share their ideas, research, and experiences in dealing with the challenges of innovative monitoring methods, joint monitoring and interpretation strategies, and numerical models.

The NovCare 2017 International Conference (Novel Methods for Subsurface Characterization and Monitoring: From Theory to Practice) took place June 6-9, 2017 at the main campus of the Technische Universität Dresden (TU Dresden), Germany. NovCare 2017 was the fifth conference in a series (Leipzig in 2009, Cape Cod in 2011, Leipzig again in 2013, and Kansas in 2015) that had proven to be an excellent forum for exchanging ideas and experiences related to the challenges of subsurface 
characterization and monitoring. The conference, organized by the TU Dresden, the Kansas Geological Survey, the Helmholtz-Centre for Environmental Research-UFZ, and the Center for Advanced Water Research (CAWR), had again a strong interdisciplinary and international flavor, with around 100 participants from 18 nations involved. Scientists, students, and practitioners closely followed 42 talks, 17 posters. Eight invited speakers delivered talks of specific relevance to one of the focus areas or discussed topics of general interest. Keynote speakers included, Albert J. Valocci (University of Illinois); Johann Fank (JRAquaConSol); Lee Slater (Rutgers University); James J. Butler Jr. (Kansas Geological Survey); Henning Prommer (CSIRO/ University of Western Australia); Gudrun Massmann (Carl von Ossietzky University of Oldenburg); Uwe Meinberg (Brandenburgische Technische Universität Cottbus-Senftenberg). These keynote presentations spanned the full breadth of the conference thematic areas from challenges and opportunities of urban water cycles, new approaches for aquifer assessment, advancing geophysical characterization of contaminated fractured rock aquifers to modeling the groundwater flow, and solute transport at the groundwater body scale or combining physically based and data-driven models for improving groundwater flow forecasts. Prof. Kamini Singha (Colorado School of Mines), the Darcy Lecturer of 2017, presented in an open public presentation a rock-physics framework, an experimental methodology, and analytical expressions that can be used to determine parameters controlling anomalous solute transport behavior from collocated hydrologic and electrical geophysical measurements in a series of settings, including groundwater and surface water/groundwater systems. Seven private companies served as sponsors and exhibited at the meeting. In addition, the meeting featured an afternoon field demonstration session showcasing direct-push methods for high-resolution subsurface characterization, sonic drilling equipment, as well as highquality soil investigation rigs and equipment. During that session, the operation of the Optical Image Profiler (OIP) producing a detailed log of UV-induced fuel fluorescence was demonstrated.

The main topics of NovCare 2017 corresponded with the objectives of this conference series and were (1) environmental sensors at all scales: how to combine information from remote-sensing, ground-based geophysics, directpush-based methods, and point sensor systems? and (2) benchmarking models with real-world data: how to get high-quality data in the field and how to use these data for reliable model predictions? The lively discussions during the formal sessions and the accompanying social events demonstrated the enthusiasm of the characterization, monitoring, and modeling communities for forums in which researchers and practitioners can come together.
Some of the presenters at NovCare 2017 used the opportunity to describe their work in a paper submitted in this thematic issue NovCare 2017.

The decrease in fresh water availability and, in contrast, the increase in water demand face enormous challenges to the water supply in several regions. Riverbank filtration (RBF), a cost-effective, natural pretreatment technology, is already used as a natural and cost-efficient water treatment method in several countries. RBF uses the bed of a reservoir, lake, or river, and an adjacent sand and gravel aquifer as a natural filter. There are several RBF applications possible with alternative well technology (e.g., horizontal or angle wells) depending on the site characteristics and soil conditions. The paper of Ghodeif et al. (2016) showed the potential for application of RBF along the Nile river in Egypt. This new paper submitted here analyzed the problems of water quality changes on bank filtration scheme, and provides an interesting case study to evaluate the potential of bank filtration for water treatment for drinking water supply in other regions, especially in Africa and Asia. Ghodeif et al. (2018) showed that even a suitable water quantity quality (compatible with the Egyptian water standards) could not guarantee the usage of the produced water for drinking water due changes in groundwater chemistry after bank filtration. The paper showed that transported organic matter can change the natural geochemical conditions and summarized that investigations regarding clogging and redox processes in the riverbed and adjacent aquifer before decision of the well-scheme location are essential.

In the study of Paufler et al. (2018), hydraulic parameters and the behavior of $\mathrm{Fe}$ and $\mathrm{Mn}$ were temporally monitored to evaluate the potential of a new RBF site in Cairo. The water quality monitoring by regularly depth-oriented sampling during regular well operation suggests that the elevated iron and nitrogen contents in the riverbed sediments are the source for iron, manganese, and ammonium in the riverbank filtrate. The authors recommend a removing of the clogging layer to improve the quality of the pumped water and testing the effect of entirely removing in front of the catchment.

With the advancement of hydrological monitoring tools and information technologies, more comprehensive and hydrological multi-parameter data sets are becoming increasingly available with improved quality and spatial coverage. Usually, the traditional data processing and visualization software are inadequate and new approaches and new algorithms need to be adapted and tailored to specific scientific needs. Joint interpretation of such "big datasets" requires new data optimization, datak standardization, and visualization approaches for a better and quickly understanding.

The paper of Haas et al. (2018) presented an approach that enables the user to standardize and visualize large amounts of groundwater time series in conjunction with other parameters such as meteorological data or river stages. Therefore, 
the approach allows a quick visualization of standardized data and, subsequently, can be used for data quality check such as identifying outliers, classifying data into different types, data comparison, and validation of the time series of hydrological data and their correlation patterns. In this paper, prospects and limitations of the approach are illustrated using various application examples were discussed and showed that this approach provides user a valuable toolbox for the quality control and data classification aspect combined with the time aspects, especially for hydrological data.

Thermal properties of soil are accurately associated with the transfer of heat throughout the soil. These properties such as thermal conductivity, specific heat and volumetric heat capacity, and thermal diffusivity can be considered one of the most important parameters for several applications in the field of engineering, climatology, and agriculture. Especially, the establishment of near surface geothermal systems shows the impact of these parameters in many engineering projects for, e.g., conditioning of residential and industrial buildings.

Di Sipio and Bertermann (2018) described an experimental testing and data analysis of a very shallow geothermal system with heat exchangers located within the first $2 \mathrm{~m}$ of depth from the ground level. This work is part of the ITER Project, funded by the European Union and focusing on very shallow geothermal (VGS) systems with low installation costs, easy maintenance over time, and less legal constraints compared to the vertical borehole heat exchangers. The paper studied the influence of sedimentary material at the disposal and varying soil moisture conditions on thermal properties on soils, showed the relationship of precipitation and natural induced temperature variations up to the freezing point, and summarized that higher water content can significantly improve the thermal conductivity and latent heat storage capacity. It was highlighted that the latent heat storage capacity is really promising if the ground temperature falls below $0{ }^{\circ} \mathrm{C}$, because the majority of the extracted heat able to satisfy the peak load demand is obtained from the solidification of the soil water. Therefore, a better knowledge of the relationship between thermal conductivity and water content is required for understanding the VSG systems behavior in saturated and unsaturated conditions.

Bertermann et al. (2018) described a new helicoidaltype ground source heat exchanger (GSHE) combining the advantages of smaller diameter drillings and the higher pipe volume per meter depth to receive a better performance of geothermal installations. This exchanger was developed and tested on six representative demonstration sites within the EU funded project CHEAP-GSHPs (Cheap and efficient application of reliable ground source heat exchangers and pumps). The paper evaluates the best combination of the new basket-type Ground Source Heat Exchanger (GSHP) and the corresponding backfilling material regarding the suitable thermal conductivity gradient between the GSHE and the surrounding soil and their cost-benefit performance.

Bertermann and Schwarz (2018) described a laboratory experiment to study the dependence of bulk density and water content on electrical conductivity. For this purpose, several experimental setups including four different pressure loads and up to 12 saturation steps were applied on three different soil types (sand, silt loam and clay). The study found a soil texture independent relation between soil moisture and electrical conductivity with a high correlation coefficient $\left(r^{2}=0.95\right)$.

Due to the success of this conference series, a sixth conference (NovCare 2019) has tentatively been scheduled for End of May 2019 at the University of Waterloo, Canada. The organizers will provide again a platform for presenting and discussing state-of-the-art developments and concepts for subsurface characterization. Further information can be found at http://www.ufz.de/novcare.

We would like to express our gratitude to the authors for their valuable contributions and for the thorough and constructive engagement of many reviewers who evaluated their submissions.

\section{References}

Bertermann D, Schwarz H (2018) Bulk density and water contentdependent electrical resistivity analyses of different soil classes on a laboratory scale. Environ Earth Sci 77:570. https://doi. org/10.1007/s12665-018-7745-3

Bertermann D, Bernardi A, Pockelé L, Galgaro A, Cultrera M, de Carli M, Müller J (2018) European project "Cheap-GSHPs": installation and monitoring of newly designed helicoidal ground source heat exchanger on the German test site. Environ Earth Sci 77:180. https://doi.org/10.1007/s12665-018-7343-4

Di Sipio E, Bertermann D (2018) Soil thermal behavior in different moisture condition: an overview of ITER project from laboratory to field test monitoring. Environ Earth Sci 77:283. https://doi. org/10.1007/s12665-018-7454-y

Ghodeif K, Grischek T, Bartak R, Wahaab R, Herlitzius J (2016) Potential of river bank filtration (RBF). Egypt Environmental Earth Sciences 75:671. https://doi.org/10.1007/s12665-016-5454-3

Ghodeif K, Paufler S, Grischek T, Wahaab R, Souaya E, Bakr M, Abogabal A (2018) Riverbank filtration in Cairo, Egypt_part I: installation of a new riverbank filtration site and first monitoring results. Environ Earth Sci 77:270. https://doi.org/10.1007/s1266 5-018-7450-2

Haas JC, Switanek M, Birk S (2018) Analysis of hydrological data with correlation matrices: technical implementation and possible applications. Environ Earth Sci 77:310. https://doi.org/10.1007/ s12665-018-7469-4

Paufler S, Grischek T, Bartak R, Ghodeif K, Wahaab R, Boernick H (2018) Riverbank filtration in Cairo, Egypt: part II-detailed investigation of a new riverbank filtration site with a focus on manganese. Environ Earth Sci 77:318. https://doi.org/10.1007/ s12665-018-7500-9 